\title{
Gene therapy for articular cartilage repair
}

S Trippel ${ }^{1 *}$, M Cucchiarini $^{2}$, H Madry ${ }^{2}$, S Shi ${ }^{1}$, and C Wang ${ }^{1}$

${ }^{1}$ Department of Orthopaedic Surgery, Indiana University School of Medicine

${ }^{2}$ Laboratory for Experimental Orthopaedics, Department of Orthopaedic Surgery, Saarland University Medical Center, Homburg/Saar, Germany

The manuscript was received on 31 August 2006 and was accepted after revision for publication on 30 January 2007.

DOI: 10.1243/09544119JEIM237

\begin{abstract}
Articular cartilage serves as the gliding surface of joints. It is susceptible to damage from trauma and from degenerative diseases. Restoration of damaged articular cartilage may be achievable through the use of cell-regulatory molecules that augment the reparative activities of the cells, inhibit the cells' degradative activities, or both. A variety of such molecules have been identified. These include insulin-like growth factor I, fibroblast growth factor 2, bone morphogenetic proteins 2, 4, and 7, and interleukin-1 receptor antagonist. It is now possible to transfer the genes encoding such molecules into articular cartilage and synovial lining cells. Although preliminary, data from in-vitro and in-vivo studies suggest that gene therapy can deliver such potentially therapeutic agents to protect existing cartilage and to build new cartilage.
\end{abstract}

Keywords: gene therapy, vectors, articular cartilage, arthritis, animal models

\section{INTRODUCTION}

Damaged articular cartilage is an unsolved problem in modern orthopaedics. Articular cartilage is the tissue which lines the weight-bearing surface of joints. Its extraordinarily low coefficient of friction enables the smooth supple pain-free motion of joints. Indeed, early in life, it is generally possible to take smooth pain-free joint motion for granted. Unfortunately, articular cartilage damage, manifested clinically as arthritis, becomes increasingly prevalent with increasing age. Arthritis afflicts over one third of Americans who are 60-65 years old, and nearly half of those 70-75 years of age [1]. Because the elderly are one of the most rapidly growing segments of the population in the USA and elsewhere, the problem of articular cartilage damage is increasing in scope. Injury to this tissue may also occur in youth. Trauma to joints can acutely damage articular cartilage. A typical example is the focal loss of articular cartilage that occurs in athletic injuries to the knee. Although less common than arthritis, this form of articular cartilage damage can be similarly disabling.

* Corresponding author: Orthopaedic Surgery, Indiana University School of Medicine, 541 Clinical Drive, Suite 600, Indianapolis, IP, 46202-5111, USA. email: strippel@iupui.edu
Articular cartilage is unusual in lacking an effective intrinsic capacity to repair itself when damaged. It lacks a blood supply and, as a result, does not have access to the reparative cells that are brought into sites of injury in nearly all other tissues in the body. Thus, defects caused by acute trauma tend to persist, and the loss of cartilage associated with arthritis tends to be inexorably progressive [2].

Current medical treatments for arthritis are highly effective in reducing the pain that it causes. However, such treatments are ineffective in reversing the course of the disease. As a result, the ultimate fate of many arthritic joints is total joint replacement surgery by implantation of metal, plastic, or ceramic bearing surfaces as substitutes for the articular cartilage surface. Although such surgery arrests the course of the disease, it does so not by restoring the cartilage to normal, but by removing it altogether. Such surgery also sets in motion a new form of progressive disease, that of joint replacement failure. Many replaced joints fail through mechanisms such as wear, loosening, infection, and breakage. This leads to further surgery to revise the replaced joint that has failed, but the results of revision joint replacement are generally not as good as those of the first replacement. In the case of focal cartilage defects resulting from acute trauma, current therapies 
include surgical recruitment of subchondral cells $[\mathbf{3}, \mathbf{4}]$, cell implantation $[\mathbf{5}, \mathbf{6}]$, and tissue implantation $[\mathbf{3}, \mathbf{5}, \mathbf{6}]$. All these treatments have had some clinical success, but none reliably restores the cartilage to normal and efforts are ongoing to improve upon current articular cartilage repair methods.

A major hurdle to the development of effective therapies for articular cartilage repair is the lack of a basic understanding of how cartilage is regulated in the normal joint and how this regulation is disrupted in the arthritic joint. Despite this limited understanding, it is possible to view the 'cause' of arthritis as an imbalance in articular cartilage homeostasis: loss of articular cartilage occurs when the level of anabolic activity in the tissue falls below the level of the catabolic activity [7]. From this perspective, one approach to reversing the progress of articular cartilage damage would be to augment articular cartilage anabolic activities and/or to reduce its catabolic activities [8].

Considerable progress has been made in the last few years in identifying biological factors that augment the reparative activity of articular chondrocytes, and also in identifying those responsible for cartilage degradation. Less progress has been made in developing methods of delivering these substances to damaged joints in a fashion that effectively restores the cartilage. For example, even when a protein that is known to stimulate cartilage repair or inhibit cartilage degradation is delivered to a joint, it may be ineffective because of rapid clearance from the joint, or difficulty getting through the articular cartilage matrix to act on the chondrocytes that it is intended to stimulate $[\mathbf{9}, \mathbf{1 0}]$. These problems may potentially be resolved by gene transfer technology.

\section{PRINCIPLES OF GENE THERAPY}

Gene therapy is based on the principle that proteins, including therapeutic proteins, are encoded by segments of deoxyribonucleic acid (DNA), or genes. A specific DNA sequence serves as a template for the synthesis of a corresponding specific messenger ribonucleic acid (mRNA). The construction of the mRNA, termed transcription, occurs within the cell's nucleus. The mRNA, in turn, serves as the template for the synthesis of a specific protein. The construction of the protein, termed translation, occurs in the cell cytoplasm. The protein may then be secreted into the extra-cellular environment. Gene therapy is simply the insertion of a gene into a cell so that the cell now manufactures (through transcription and then translation) the desired protein.
The specific goal of the gene therapy determines the specific protein, and hence the specific gene, selected for use. A growth factor gene may be used if the goal of gene therapy is to alter the behaviour of surrounding cells. A gene encoding an enzyme inhibitor may be selected if the goal is to inhibit cartilage matrix degradation. Gene therapy may be viewed as a drug delivery system that is able to deliver an essentially pure agent to a highly specific location in a delayed-release fashion. The technology for achieving gene transfer and protein production is, however, not simple and is still under development.

\section{SELECTION OF GENES FOR GENE THERAPY}

An important advantage of gene transfer as a potential approach to therapy for cartilage repair is the wide variety of molecules that have been found to augment the anabolic activity of articular chondrocytes. Most of these molecules are proteins that function as cell-signalling agents that regulate cell behaviour. Harnessing this action has been achieved for several growth factors in in-vitro and in-vivo models. Insulin-like growth factor I (IGF-I) stimulates synthesis by chondrocytes of the two major building blocks of articular cartilage: aggrecan [11] and type II collagen [12]. It also has a mild stimulatory effect on chondrocyte proliferation and inhibits chondrocyte degradation of its surrounding matrix [13]. Fibroblast growth factor 2 (FGF-2) is mitogenic for chondrocytes but appears to be capable of stimulating both reparative and degradative behaviour in articular cartilage [8]. Members of the transforming growth factor (TGF- $\beta$ ) superfamily, including the bone morphogenetic proteins (BMPs), are potent regulators of chondrocytes. For example, in vitro, BMP-2 maintained the articular chondrocyte phenotype in a long-term culture [14] and, in vivo, BMP-2 significantly improved the repair of articular cartilage defects in rabbit knees analysed 1 year after treatment [15].

\section{CULTURE MODELS OF GENE TRANSFER}

In-vitro models of chondrocyte gene transfer include two-dimensional and three-dimensional cell cultures. The effect of overexpression of several genes has been studied in two-dimensional models, including IGF-I [16-18], BMP-2 [18], and TGF- $\beta-1[\mathbf{1 8}, 19]$. Three-dimensional systems more closely resemble the in-vivo environment of native chondrocytes 
embedded within their matrix. These conditions enable chondrocytes to assume a spherical shape and to avoid the phenotypic drift that may occur when chondrocytes are grown and passaged over extended periods of time in monolayer $[\mathbf{2 0}, \mathbf{2 1}]$. Three-dimensional systems that have been used for gene transfer include pellet cultures [22], the transplantation of genetically modified chondrocytes on to cartilage explants [23-26], the creation of genetically modified tissue-engineered cartilage by attaching modified chondrocytes to biomaterials such as polyglycolic acid [27], or the encapsulation of genetically modified chondrocytes in hydrogels such as alginate [28-31].

The transplantation of genetically modified chondrocytes on to articular cartilage explants in vitro creates a chimeric tissue composed of modified cells transplanted on to articular cartilage [23-26, 32]. This model permits the study of the effect of a potential therapeutic gene on the formation of new cartilaginous tissue as well as on the underlying host cartilage. Transplantation of articular chondrocytes that overexpressed human IGF-I was shown in such a model to both stimulate chondrocyte proliferation and matrix synthesis in the new tissue, and to increase DNA and glycosaminoglycan synthesis by the underlying explant cartilage chondrocytes. These results suggest a paracrine effect of the secreted gene product on distant chondrocytes embedded within their native matrix [26]. Transplantation of chondrocytes transduced with an adenoviral BMP-7 vector also led to thicker new tissue in this model, suggesting an enhanced matrix synthesis [24]. In contrast, when chondrocytes overexpressing human FGF-2 were transplanted, the cells in the new tissue showed a selective stimulation of mitogenic without effects on matrix synthesis [25].

Cartilage tissue engineering may also be improved by the application of gene transfer technology. Transfection of articular chondrocytes with human IGF-I complementary deoxyribonucleic acid (cDNA) augmented the structural and functional properties of tissue engineered cartilaginous constructs based on a polyglycolic acid scaffold and generated in a bioreactor [27]. The biosynthetic activity of chondrocytes encapsulated in alginate spheres was enhanced by IGF-I [31] and FGF-2 [29] gene transfer. Similarly, the transfer of SOX9, a transcription factor that acts only intracellularly, stimulated type-II collagen expression in alginate spheres [33], and in pellet cultures [22]. This finding suggests that tissue engineering coupled with gene therapy based on intracrine mechanisms may be feasible.

\section{ANIMAL MODELS OF GENE TRANSFER}

Among the first genes to be investigated in vivo was interleukin-1 receptor antagonist (IL-1Ra). Interleukin-1 is a cytokine produced by synovial cells and chondrocytes that appears to incite cartilage damage in arthritis [34]. IL-1Ra is a protein that inhibits the catabolic actions of interleukin-1. IL-1Ra gene therapy has been investigated in mouse [35], rat [36], rabbit [37-39], canine [40], and equine [41] models of cartilage damage. The treatment reduced articular cartilage damage [38-40] and also reduced clinical signs of disease in the equine model [41]. IL-1Ra was also used in the first human arthritis gene therapy trial [42]. In this study, the IL-1Ra gene was delivered in autologous synovial cells to the hand joints of patients with rheumatoid arthritis. At the time of joint surgery 1 week later, the IL-1Ra gene was shown to be expressed and IL-Ra protein was found in the joint.

Other promising candidates for gene therapy are growth factors that stimulate anabolic activities by articular chondrocytes. These include IGF-I, FGF-2, TGF- $\beta$, BMP-2, and BMP-7. IGF-I gene transfer into articular chondrocytes stimulated chondrocyte proliferation and matrix synthesis and augmented the formation of neocartilage in in-vitro $[\mathbf{1 6}, \mathbf{2 6}]$ and in-vivo [31, 43, 44] models of articular cartilage repair. Similar results have been obtained with FGF-2 in vitro [25] and in vivo [45-47]. Direct intra-articular transfer of the TGF- $\beta$ gene raised intra-articular TGF- $\beta$ protein levels $[\mathbf{4 8}]$ and intra-articular injection of fibroblasts transduced with the TGF- $\beta$ gene stimulated cartilage repair in a cartilage defect model [49]. Conversely, intra-articular gene transfer of a TGF- $\beta$ inhibitor increased articular cartilage proteoglycan loss [50]. Gene transfer using BMP-2 [43], BMP-4 [51], and BMP-7 [52, 53] augmented intra-articular cartilage formation in in-vivo models.

\section{TYPES OF GENE THERAPY}

\subsection{In-vitro gene therapy}

In-vitro gene therapy entails the insertion of the desired gene (transgene) into the recipient cells in a cell or tissue culture environment. The cells are then placed into the relevant site in the body. This has the advantage of enabling gene transfer into a specific population of cells, and the ability to test the cells for successful gene expression. In-vitro methods have been used to deliver reporter genes [54], IGF-I [16, 26], FGF-2 [25], BMP-2 [43], BMP-4 [51], BMP-7 
$[\mathbf{5 2}, \mathbf{5 3}]$, TGF- $\beta$ [49], and IL-1Ra [35, 37]. This is the approach that was approved and then used in the published human gene therapy study of IL-1Ra for rheumatoid arthritis of the hand [42]. When using adenoviral vectors, the in-vitro method has been shown to reduce the immune response that this vector may elicit when used by in-vivo methods [43]. In-vitro gene therapeutic approaches also have the advantage of delivering cells that may contribute to the repair process. This may be of particular value for the treatment of focal articular cartilage defects using anabolic factors such as IGF-I, FGF-2, and TGF- $\beta$, in which cells are needed to fill the site of damage.

\subsection{In-vivo gene therapy}

In-vivo gene therapy involves the delivery of the desired gene directly into the body. This method has the advantage of avoiding the extra steps involved in cell harvest, isolation, culture, and subsequent delivery. In theory, it should reduce the risk of complications such as cell contamination or phenotypic shifts, and the magnitude of processing costs. In-vivo approaches may be particularly suitable for gene delivery to the synovium because these cells are readily accessible to injected agents. Articular chondrocytes, in contrast, are embedded within a matrix that restricts diffusion of injected agents and may be expected to limit the access of such agents to the chondrocytes. This approach has been applied in cartilage damage models to the delivery of IL-1Ra [36, 38, 39, 41], BMP-2 [43], IGF-I [44], FGF-2 [46], TGF- $\beta$ inhibitor [50], interleukin-4 [55], and the soluble tumour necrosis factor receptor 1 [56].

Localized in-vivo gene therapy could, in theory, reduce the disadvantages of systemic viral dissemination. When adeno-associated virus (AAV) vectors were applied to articular cartilage defects by open arthrotomy in the rat [57] or rabbit [46] knee, transgene product was subsequently found in the defect repair tissue but, in both models, transgene product was also noted in the synovium. These results indicate that, even with localized in-vivo delivery into a joint, at least some systemic distribution may occur.

\section{GENE DELIVERY AGENTS}

\subsection{Non-viral gene delivery}

A popular approach to transferring DNA into cells employs physicochemical methods. Electroporation enables DNA to cross the cells membrane by generat- ing a charge differential across the cell membrane. Although this method has been applied to chondrocytes [58], its use has not been widespread. A variety of cationic liposomes and other lipid-based systems have developed for gene transfer and are commercially available. In a study that systematically compared the ability of several cationic lipid preparations to transfect bovine articular chondrocytes, considerable differences were found among these reagents [59]. Transfection with these lipid-based reagents may be substantially increased by the use of cotransfection agents [59]. Thus, a limitation of these reagents is their sensitivity to cell type and transfection conditions. Such non-viral gene transfer methods have the advantage of avoiding the risk of insertional mutagenesis of retroviruses, the risk of immunogenicity of adenoviruses, or the size limitation on transferred DNA that is associated with AAVs. Non-viral methods also avoid the risk of acquiring viral competence. Because non-viral gene transfer does not place the therapeutic gene into the cell genome, the transferred gene (transgene) is not transmitted to daughter cells if the cell divides. The episomal (not integrated into the host cell genome) location of the transgene also destines the transgene to be expressed for only a transient time period. This transient expression is of great safety value for anabolic genes whose product could cause excessive growth if overexpressed for prolonged periods. However, this feature also limits the potential value of the method for chronic disorders that require longlasting output of the gene product.

\subsection{Viral gene delivery}

Viruses in nature evolved to transfer genetic material. The life cycle of wild-type viruses involves the transfer of viral DNA or RNA into host cells. Virus-based gene therapy builds on this innate ability by adding potentially therapeutic genes to the viral sequence and, in some instances, by also removing portions of the viral genome that enable the viruses to be harmful.

\subsection{Retrovirus vectors}

Retroviruses include such evolutionarily successful viruses as human immunodeficiency virus and human T-lymphotropic viruses. An important advantage of these viruses for gene therapy is their ability to incorporate into the genome of the host cell. This enables the transferred gene to be replicated during cell division and to achieve long-term expression over multiple cell generations. However, this feature also imposes the safety issue of insertional mutagenesis. 
This may occur when the transferred gene is inserted into a region of the host cell's DNA in such a way that the insertion disrupts the function of a normal gene. For example, by disrupting the function of a tumour suppressor gene, the gene transfer may inadvertently promote cancer. This phenomenon has been blamed for the development of leukaemia in some children who received retroviral gene therapy in the late 1990s [60]. Additional limitations of retroviruses as vectors are their inability to infect non-dividing cells and the need for special culture procedures to identify and select cells that contain the transgene. Retroviruses have, however, been demonstrated to be feasible vectors for delivering exogenous genes to sites of articular cartilage damage [51, 61].

\subsection{Adenovirus vectors}

Adenovirus vectors are among the most successful vectors available for gene transfer. They often generate high transfection efficiency and high levels of transgene product in a variety of cell types. Adenoviral vectors have been used in in-vitro and in-vivo models of cartilage damage, including models of inflamatory arthritis $[44]$, osteoarthritis $[41,48]$, and chondral defects $[\mathbf{3 2}, \mathbf{5 3}, \mathbf{6 2}]$. They are the only viral vector used to date in human joint disease [42]. Unfortunately, adenoviral vectors are often immunogenic and may stimulate a host response. This reaction may be severe and led to the highly publicized death of a gene therapy patient in a phase I clinical trial [63]. Even in milder form, this phenomenon may be problematic. In the field of cartilage gene therapy, it is thought to be responsible for the paradoxical inhibition of proteoglycan synthesis in chondrocytes that received the IL-1Ra gene, a treatment that would be expected to have the opposite effect [64].

\subsection{Adeno-associated virus vectors}

AAVs are replication-defective parvoviruses that have the advantage, for gene therapy, of being nonpathogenic in humans. They lack the immunogenicity of adenoviruses and the risk of insertional mutagenesis of retroviruses. Early experience with recombinant AAVs suggests that these viruses may serve as effective vectors for chondrocyte and synovial cell transfection in vitro $[\mathbf{4 5}, \mathbf{5 7}, \mathbf{6 5}]$ and in vivo $[36,46,47,55,56,66,67]$. To date, however, available data on these vectors remains limited in comparison with adenoviral vectors. Both an advantage and a limitation of AAVs as a gene therapy vector is its size. As a particularly small virus, it may have access to sites that are not accessible to larger viral vectors. However, its size also means that it can hold only relatively small (up to about 4.7 kilobases) genes. This limitation may be resolved by exploiting the attractive feature of rAAV genomes that they can be linked together to increase the size of the genes to be transferred $[\mathbf{6 8}, \mathbf{6 9}]$.

\subsection{Lentivirus vectors}

Lentiviruses are a relative of retroviruses. Lentivirus vectors are distinguished from oncogenic retrovirus vectors by their ability to transduce non-dividing cells. Lentivirus vector-based gene delivery can generate long-term transgene expression by incorporating transgenes into the host cell genome. Two additional advantages of these vectors are their ability to deliver large cDNAs into target cells and to do so without inducing a host immune response against the transduced cells [70]. Lentivirus vectors have been successfully used to deliver genes to synovium in vivo [71] and to chondrocytes in vitro [72]. The safety of these vectors and the regulation of expression of their transgenes are currently under investigation.

\section{FUTURE DIRECTIONS}

The potential applications of gene therapy for cartilage repair are many. Gene transfer technology can, in theory, be applied to inflammatory joint disease such as rheumatoid arthritis, degenerative joint disease such as osteoarthritis or post-traumatic arthritis, and to acute cartilage loss, such as damage due to athletic injuries. Considerable progress has been made in bringing these applications towards fruition in articular cartilage disease. The technology has been shown to be effective at a proof-of-concept level for all these applications in both in-vitro and in-vivo models. However, many unanswered questions remain (Table 1). What is the optimal vector? Is in-vivo gene therapy superior to in-vitro gene therapy, or vice versa? What is the short-term and, perhaps more importantly, the long-term safety of the genes and gene products that would be used to treat joint disease? Is gene transfer technology robust enough to be useful on its own, or should efforts be intensified to combine it with tissue engineering technology? Probably, the answer to all of these questions is 'it depends'. Just as the disorders that afflict cartilage are diverse and of multifactorial aetiology, so effective treatments for them will be diverse and will probably require multiple elements. As ongoing research provides answers to these questions, and as understanding of the mechanisms underlying 
Table 1 Progress in articular cartilage gene therapy

\begin{tabular}{ll}
\hline Accomplished & To be accomplished \\
\hline Gene transfer to articular chondrocytes & Optimal gene transfer method \\
Transgene protein production by chondrocytes & Best protein(s) to transfer \\
Enhanced chondrogenesis in vitro & Long-term safety \\
Enhanced chondrogenesis in vivo (animal models) & Durable efficacy \\
& Human applicability \\
\hline
\end{tabular}

cartilage disease improves, gene therapy may become an integral part of the armamentarium for treating articular cartilage damage.

\section{ACKNOWLEDGEMENTS}

This work was supported in part by National Institutes of Health-National Institute of Arthritis and Musculoskeletal and Skin Diseases grant AR047702 and the Indiana 21st Century Research and Technology fund.

\section{REFERENCES}

1 Praemer, A., Furner, S., and Rice, D. P. Musculoskeletal conditions in the United States, 1999 (American Academy of Orthopaedic Surgeons, Rosemont, Illinois).

2 Mankin, H. J. and Buckwalter, J. A. Restoration of the osteoarthrotic joint. J. Bone Jt Surg. Am., 1996, 78, $1-2$.

3 Gudas, R., Kalesinskas, R. J., Kimtys, V., Stankevičius, E., Toliušis, V., Bernotavičius, G., and Smailys, A. A prospective randomized clinical study of mosaic osteochondral autologous transplantation versus microfracture for the treatment of osteochondral defects in the knee joint in young athletes. Arthroscopy: J. Arthroscopic Related Surg., 2005, 21 (9), 1066-1075.

4 Knutsen, G., Engebretsen, L., Ludvigsen, T. C., Drogset, J. O., Grøntvedt, T., Solheim, E., Strand, T., Roberts, S., Isaksen, V., and Johansen, O. Autologous chondrocyte implantation compared with microfracture in the knee. J. Bone Jt Surg. Am., 2004, 86(3), 455-464.

5 Bentley, G., Biant, L. C., Carrington, R. W., Akmal, M., Goldberg, A., Williams, A. M., Skinner, J. A., and Pringle, J. A prospective randomized comparison of autologous chondrocyte implantation versus mosaicplasty for osteochondral defects in the knee. J. Bone Jt Surg. Br., 2003, 85, 223-230.

6 Horas, U., Pelinkovic, D., Herr, G., Aigner, T., and Schnettler, R. Autologous chondrocyte implantation and osteochondral cylinder transplantation in cartilage repair of the knee joint. J. Bone Jt Surg. Am., 2003, 85(2), 185-192.
7 Trippel, S. B. Growth factor actions on articular cartilage. J. Rheumatology, 1995, 22 (Suppl. 43), 129-132.

8 Trippel, S. B., Coutts, R. D., Einhorn, T. A., Mundy, G. R., and Rosenfeld, R. Instructional course lectures: growth factors as therapeutic agents. J. Bone Jt Surg. Am., 1996, 78, 1272-1286.

9 Garcia, A. M., Lark, M. W., Trippel, S. B., and Grodzinsky, A. J. Transport of tissue inhibitor of metalloproteinase-1 through cartilage: contributions of fluid flow and electrical migration. J. Orthop. Res., 1998, 16, 734-742.

10 Garcia, A. M., Szasz, N., Trippel, S. B., Morales, T. I., Grodzinsky, A. J., and Frank, E. H. Transport and binding of IGF-I through articular cartilage. Arch. Biochemistry Biophysics, 2003, 415, 69-79.

11 McQuillan, D. J., Handley, C. J., Campbell, M. A., Bolis, S., Milway, V. E., and Herington, A. C. Stimulation of proteoglycan biosynthesis by serum and insulin-like growth factor I in cultured bovine articular cartilage. Biochem. J., 1986, 240, 423-430.

12 Sandell, L. J. and Dudek, E. J. Insulin-like growth factor I stimulates type II collagen gene expression in cultured chondrocytes. Orthop. Trans., 1988, 12, 377-378.

13 Sah, R. L., Chen, A. C., Grodzinsky, A. J., and Trippel, S. B. Differential effects of bFGF and IGF-1 on matrix metabolism in calf and adult bovine cartilage explants. Arch. Biochemistry Biophysics, 1994, 308(1), 137-147.

14 Sailor, L. Z., Hewick, R. M., and Morris, E. A. Recombinant human bone morphogenetic protein-2 maintains the articular chondrocyte phenotype in long-term culture. J. Orthop. Res., 1996, 14(6), 937-945.

15 Sellers, R. S., Zhang, R., Glasson, S. S., Kim, H. D., Peluso, D., D'Augusta, D. A., Beckwith, K., and Morris, E. A. Repair of articular cartilage defects one year after treatment with recombinant human bone morphogenetic protein-2 (rhBMP-2). J. Bone Jt Surg. Am., 2000, 82(2), 151-160.

16 Brower-Toland, B. D., Saxer, R. A., Goodrich, L. R., Mi, Z., Robbins, P. D., Evans, C. H., and Nixon, A. J. Direct adenovirus-mediated insulin-like growth factor I gene transfer enhances transplant chondrocyte function. Hum. Gene Therapy, 2001, 12(2), $117-129$.

17 Nixon, A. J., Brower-Toland, B. D., Bent, S. J., Saxer, R. A., Wilke, M. J., Robbins, P. D., and Evans, C. H. Insulinlike growth factor-I gene therapy applications 
for cartilage repair. Clin. Orthop. Related Res., 2000, 379 (Suppl.), S201-S213.

18 Smith, P., Shuler, F. D., Georgescu, H. I., Ghivizzani, S. C., Johnstone, B., Niyibizi, C., Robbins, P. D., and Evans, C. H. Genetic enhancement of matrix synthesis by articular chondrocytes: comparison of different growth factor genes in the presence and absence of interleukin-1. Arthritis Rheum., 2000, 43(5), 1156-1164.

19 Shuler, F. D., Georgescu, H. I., Niyibizi, C., Studer, R. K., Mi, Z., Johnstone, B., Robbins, R. D., and Evans, C. H. Increased matrix synthesis following adenoviral transfer of a transforming growth factor betal gene into articular chondrocytes. J. Orthop. Res., 2000, 18(4), 585-592.

20 Benya, P. D., Padilla, S. R., and Nimni, M. E. Independent regulation of collagen types by chondrocytes during the loss of differentiated function in culture. Cell, 1978, 15(4), 1313-1321.

21 von der Mark, K., Gauss, V., von der Mark, H., and Mueller, P. Relationship between cell shape and type of collagen synthesis as chondrocytes lose their cartilage phenotype in culture. Nature, 1977, 267, 531-532.

22 Tew, S. R., Li, Y., Pothacharoen, P., Tweats, L. M., Hawkins, R. E., and Hardingham, T. E. Retroviral transduction with SOX9 enhances re-expression of the chondrocyte phenotype in passaged osteoarthritic human articular chondrocytes. Osteoarthritis Cartilage, 2005, 13(1), 80-89.

23 Doherty, P. J., Zhang, H., Tremblay, L., Manolopoulos, V., and Marshall, K. W. Resurfacing of articular cartilage explants with geneticallymodified human chondrocytes in vitro. Osteoarthritis Cartilage, 1998, 6(3), 153-159.

24 Hidaka, C., Quitoriano, M., Warren, R. F., and Crystal, R. G. Enhanced matrix synthesis and in vitro formation of cartilage-like tissue by genetically modified chondrocytes expressing BMP-7. J. Orthop. Res., 2001, 19(5), 751-758.

25 Madry, H., Emkey, G., Zurakowski, D., and Trippel, S. B. Overexpression of human fibroblast growth factor 2 stimulates cell proliferation in an ex vivo model of articular chondrocyte transplantation. $J$. Gene Medicine, 2004, 6(2), 238-245.

26 Madry, H., Zurakowski, D., and Trippel, S. B. Overexpression of human insulin-like growth factor-I promotes new tissue formation in an ex vivo model of articular chondrocyte transplantation. Gene Therapy, 2004, 8, 1443-1449.

27 Madry, H., Padera, B., Seidel, J., Freed, L., Langer, R., Trippel, S. B., and Vunjak-Novakovic, G. Gene transfer of a human insulin-like growth factor I cDNA enhances tissue engineering of cartilage. Hum. Gene Therapy, 2002, 13, 1621-1630.

28 Diduch, D. R., Jordan, L. C., Mierisch, C. M., and Balian, G. Marrow stromal cells embedded in alginate for repair of osteochondral defects. Arthroscopy, 2000, 16(6), 571-577.

29 Kaul, G., Cucchiarini, M., Arntzen, D., Zurakowski, D., Menger, M. D., Kohn, D., Trippel, S. B., and
Madry, H. Local stimulation of articular cartilage repair by transplantation of encapsulated chondrocytes overexpressing human fibroblast growth factor 2 (FGF-2) in vivo. J. Gene Medicine, 2006, 8(1), $100-111$.

30 Madry, H., Cucchiarini, M., Stein, U., Remberger, K., Menger, M. D., Kohn, D., and Trippel, S. B. Sustained transgene expression in cartilage defects in vivo after transplantation of articular chondrocytes modified by lipid-mediated gene transfer in a gel suspension delivery system. J. Gene Medicine, 2003, 5(6), 502-509.

31 Madry, H., Kaul, G., Cucchiarini, M., Stein, U., Zurakowski, D., Remberger, K., Menger, M. D., Kohn, D., and Trippel, S. B. Enhanced repair of articular cartilage defects in vivo by transplanted chondrocytes overexpressing insulin-like growth factor I (IGF-I). Gene Therapy, 2005, 12(14), 11711179.

32 Baragi, V. M., Renkiewicz, R. R., Jordan, H., Bonadio, J., Hartman, J. W., and Roessler, B. J. Transplantation of transduced chondrocytes protects articular cartilage from interleukin 1-induced extracellular matrix degradation. J. Clin. Invest., 1995, 96(5), 2454-2460.

33 Li, Y., Tew, S. R., Russell, A. M., Gonzalez, K. R., Hardingham, T. E., and Hawkins, R. E. Transduction of passaged human articular chondrocytes with adenoviral, retroviral, and lentiviral vectors and the effects of enhanced expression of SOX9. Tissue Engng, 2004, 10(3-4), 575-584.

34 MacDonald, M. H., Stover, S. M., Willits, N. H., and Benton, H. P. Regulation of matrix metabolism in equine cartilage explant cultures by interleukin-1. Am. J. Vet. Res., 1992, 53, 2278-2285.

35 Muller-Ladner, U., Roberts, C. R., Franklin, B. N., Gay, R. E., Robbins, P. D., Evans, C. H., and Gay, S. Human IL-Ira gene transfer into human synovial fibroblasts is chondroprotective. J. Immunology, 1997, 158, 3492-3498.

36 Pan, R. Y., Chen, S. L., Xiao, X., Liu, D. W., Peng, H. J., and Tsao, Y. P. Therapy and prevention of arthritis by recombinant adeno-associated virus vector with delivery of interleukin-1 receptor antagonist. Arthritis Rheum., 2000, 43(2), 289-297.

37 Bandara, G., Mueller, G. M., Galea-Lauri, J., Tindal, M. H., Georgescu, H. I., Suchanek, M. K., Hung, G. L., Glorioso, J. C., Robbins, P. D., and Evans, C. H. Intraarticular expression of biologically active interleukin 1-receptor-antagonist protein by ex vivo gene transfer. Proc. Natn. Acad. Sci. USA, 1993, 90, 10764-10768.

38 Zhang, X., Mae, Z., and Yu, C. Suppression of early experimental osteoarthritis by gene transfer of interleukin-1 receptor antagonist and interleukin-10. J. Orthop. Res., 2004, 22, 742-750.

39 Fernandes, J., Tardif, G., Martel-Pelletier, J., Lascau-Coman, V., Dupuis, M., Moldovan, F., Sheppard, M., Krishnan, B. R., and Pelletier, J. P. In vivo transfer of interleukin-1 receptor antagonist gene in osteoarthritic rabbit knee joints. Am. J. Pathology, 1999, 154(4), 1159-1169. 
40 Pelletier, J. P., Caron, J. P., Evans, C. H., Robbins, P. D., Georgescu, H. I., Jovanovic, D., Fernandes, J. C., and Martel-Pelletier, J. In vivo suppression of early experimental osteoarthritis by IL-Ra using gene therapy. Arthritis Rheum., 1997, 40, 1012-1019.

41 Frisbie, D. D., Ghivizzani, S. C., Robbins, P. D., Evans, C. H., and McIlwraith, C. W. Treatment of experimental equine osteoarthritis by in vivo delivery of the equine interleukin-1 receptor antagonist gene. Gene Therapy, 2002, 9, 12-20.

42 Evans, C. H., Robbins, P. D., Ghivizzani, S. C., Wasko, M. C., Tomaino, M. M., Kang, R., Muzzonigro, T. A., Vogt, M., Elder, E. M., Whiteside, T. L., Watkins, S. C., and Herndon, J. H. Gene transfer to human joints: progress toward a gene therapy of arthritis. Proc. Natn. Acad. Sci. USA, 2005, 102(24), 8698-8703.

43 Gelse, K., Jiang, Q. J., Aigner, T., Ritter, T., Wagner, K., Pöschl, E., von der Mark, K., and Schneider, H. Fibroblast-mediated delivery of growth factor complementary DNA into mouse joints induces chondrogenesis but avoids the disadvantages of direct viral gene transfer. Arthritis Rheum., 2001, 44(8), 1943-1953.

44 Mi, Z., Ghivizzani, S. C., Lechman, E. R., Jaffurs, D., Glorioso, J. C., Evans, C. H., and Robbins, P. D. Adenovirus-mediated gene transfer of insulin-like growth factor 1 stimulates proteoglycan synthesis in rabbit joints. Arthritis Rheum., 2000, 43(11), 2563-2570.

45 Cucchiarini, M., Madry, H., Ma, C., Thurn, T., Zurakowski, D., Menger, M. D., Kohn, D., Trippel, S. B., and Terwilliger, E. F. Improved tissue repair in articular cartilage defects in vivo by rAAVmediated overexpression of human fibroblast growth factor 2. Molecular Therapy, 2005, 12 , 229-238.

46 Hiraide, A., Yokoo, N., Xin, K., Okuda, K., Mizukami, H., Ozawa, K., and Saito, T. Repair of articular cartilage defect by intraarticular administration of basic fibroblast growth factor gene, using adeno-associated virus vector. Hum. Gene Therapy, 2005, 16, 1413-1421.

47 Yokoo, N., Saito, T., Uesugi, M., Kobayashi, N., Xin, K. Q., Okuda, K., Mizukami, H., Ozawa, K., and Koshino, T. Repair of articular cartilage defect by autologous transplantation of basic fibroblast growth factor gene-transduced chondrocytes with adeno-associated virus vector. Arthritis Rheum., 2005, 52(1), 164-170.

48 Ikeda, T., Kubo, T., Arai, Y., Nakanishi, T., Kobayashi, K., Takahashi, K., Imanishi, J., Takigawa, M., and Hirasawa, Y. Adenovirus mediated gene delivery to the joints of guinea pigs. J. Rheumatology, 1998, 25, 1666-1673.

49 Lee, K. H., Song, S. U., Hwang, T. S., Yi, Y., Oh, I. S., Lee, J. Y., Choi, K. B., Choi, M. S., and Kim, S. J. Regeneration of hyaline cartilage by cell-mediated gene therapy using transforming growth factor beta 1-producing fibroblasts. Hum. Gene Therapy, 2001, 12, 1805-1813.
50 Scharstuhl, A., Vitters, E. L., van der Kraan, P. M., and van den Berg, W. B. Reduction of ostephyte formation and synovial thickening by adenoviral overexpression of transforming growth factor $\beta /$ bone morphogenetic protein inhibitors during experimental osteoarthritis. Arthritis Rheum., 2003, 48(12), 3442-3451.

51 Kuroda, R., Usas, A., Kubo, S., Corsi, K., Peng, H., Rose, T., Cummins, J., Fu, F. H., and Huard, J. Cartilage repair using bone morphogenetic protein 4 and muscle-derived stem cells. Arthritis Rheum., 2006, 54(2), 433-442.

52 Grande, D. A., Mason, J., Light, E., and Dines, D. Stem cells as platforms for delivery of genes to enhance cartilage repair. J. Bone Jt Surg. Am., 2003, 85 (Suppl. 2), 111-116.

53 Hidaka, C., Goodrich, L. R., Chen, C., Warren, R. F., Crystal, R. G., and Nixon, A. J. Acceleration of cartilage repair by genetically modified chondrocytes over expressing bone morphogenetic protein-7. J. Orthop. Res., 2003, 21, 573-583.

54 Roessler, B. J., Allen, E. D., Wilson, J. M., Hartman, J. W., and Davidson, B. L. Adenoviral-mediated gene transfer to rabbit synovium in vivo. J. Clin. Invest., 1993, 92(2), 1085-1092.

55 Watanabe, S., Imagawa, T., Boivin, G. P., Gao, G., Wilson, J. M., and Hirsch, R. Adeno-associated virus mediates long-term gene transfer and delivery of chondroprotective IL-4 to murine synovium. Molecular Therapy, 2000, 2(2), 147-152.

56 Zhang, H. G., Xie, J., Yang, P., Wang, Y., Xu, L., Liu, D., Hsu, H., Zhou, T., Edwards, C. A. III, and Mountz, J. D. Adeno-associated virus production of soluble tumor necrosis factor receptor neutralizes tumor necrosis factor alpha and reduces arthritis. Hum. Gene Therapy, 2000, 11, 2431-2442.

57 Madry, H., Cucchiarini, M., Terwilliger, E. F., and Trippel, S. B. Recombinant adeno-associated vectors efficiently and persistently transduce chondrocytes in normal and osteoarthritic human articular cartilage. Hum. Gene Therapy, 2003, 14, 393-402.

58 Tsuru, M., Nagata, K., Ueno, T., Jimi, A., Noda, S., Iida, S., and Sata, M. Confocal laser microscopy of chondrocytes that received gene transfer using in vitro electroporation. Kurume Med. J., 2002, 49(1-2), 1-5.

59 Madry, H. and Trippel, S. B. Efficient lipid-mediated gene transfer to articular chondrocytes. Gene Therapy, 2000, 7, 286-291.

60 Hacein-Bey-Abina, S., Von Kalle, C., Schmidt, M., McCormack, M. P., Wulffraat, N., Leboulch, P., Lim, A., Osborne, C. S., Pawliuk, R., Morillon, E., Sorensen, R., Forster, A., Fraser, P., Cohen, J. I., de Saint Basile, G., Alexander, I., Wintergerst, U., Frebourg, T., Aurias, A., Stoppa-Lyonnet, D., Romana, S., Radford-Weiss, I., Gross, F., Valensi, F., Delabesse, E., Macintyre, E., Sigaux, F., Soulier, J., Leiva, L. E., Wissler, M., Prinz, C., Rabbitts, T. H., Le Deist, F., Fischer, A., and Cavazzana-Calvo, M. LMO2-associated clonal $\mathrm{T}$ cell proliferation in two patients after gene therapy for SCID-X1. Science, 2003, 302, 415-419. 
61 Kang, R., Marui, T., Ghivizzani, S. C., Nita, I. M., Georgescu, H. I., Suh, J. K., Robbins, P. D., Evans, C. H., and Ferguson, A. B. Jr Ex vivo gene transfer to chondrocytes in full-thickness articular cartilage defects: a feasibility study. Osteoarthritis Cartilage, 1997, 5, 139-143.

62 Ikeda, T., Kubo, T., Nakanishi, T., Arai, Y., Kobayashi, K., Mazda, O., Ohashi, S., Takahashi, K., Imanishi, J., Takigawa, M., and Hirasawa, Y. Ex vivo gene delivery using an adenovirus vector in treatment for cartilage defects. J. Rheumatology, 2000, 27, 990-996.

63 Dettweiler, U. and Simon, P. Points to consider for ethics committees in human gene therapy trials. Bioethics, 2001, 15(5-6), 491-500.

64 Nixon, A. J., Haupt, J. L., Frisbie, D. D., Morisset, S. S., McIlwraith, C. W., Robbins, P. D., Evans, C. H., and Ghivizzani, S. Gene-mediated restoration of cartilage matrix by combination insulin-like growth factor-I/interleukin-1 receptor antagonist therapy. Gene Therapy, 2005, 12, 177-186.

65 Madry, H., Cucchiarini, M., Kaul, G., Kohn, D., Terwilliger, E. F., and Trippel, S. B. Menisci are efficiently transduced by recombinant adenoassociated virus vectors in vitro and in vivo. Am. J. Sports Medicine, 2004, 32, 1860-1865.

66 Goater, J., Muller, R., Kollias, G., Firestein, G. S., Sanz, I., O'Keefe, R. J., and Schwarz, E. M. Empirical advantages of adeno associated viral vectors for in vivo gene therapy for arthritis. J. Rheumatology, 2000, 27(4), 983-989.

67 Ulrich-Vinther, M., Duch, M. R., Soballe, K., O'Keefe, R. J., Schwarz, E. M., and Pedersen, F. S. In vivo gene delivery to articular chondrocytes mediated by an adeno-associated virus vector. J. Orthop. Res., 2004, 22(4), 726-734.

68 Duan, D., Yue, Y., Yan, Z., and Engelhardt, J. F. A new dual-vector approach to enhance recombinant adeno-associated virus-mediated gene expression through intermolecular cis activation. Nature Medicine, 2000, 6(5), 595-598.

69 Yan, Z., Zhang, Y., Duan, D., and Engelhardt, J. F. Trans-splicing vectors expand the utility of adenoassociated virus for gene therapy. Proc. Natn. Acad. Sci. USA, 2000, 97(12), 6716-6721.

70 Kafri, T. Lentivirus vectors: difficulties and hopes before clinical trials. Curr. Opin. Molecular Therapy, 2001, 4(3), 316-326.

71 Gouze, E., Pawliuk, R., Pilapil, C., Gouze, J. N., Fleet, C., Palmer, G. D., Evans, C. H., Leboulch, P., and Ghivizzani, S. C. In vivo gene delivery to synovium by lentiviral vectors. Molecular Therapy, 2002, 5(4), 397-404.

72 Lu, F. Z., Kitazawa, Y., Hara, Y., Jiang, J. Y., and Li, $\mathbf{X}$. K. Long-term gene expression using the lentiviral vector in rat chondrocytes. Clin. Orthop. Related Res., 2005, 439, 243-252. 
Copyright of Proceedings of the Institution of Mechanical Engineers -- Part H -- Journal of Engineering in Medicine is the property of Professional Engineering Publishing and its content may not be copied or emailed to multiple sites or posted to a listserv without the copyright holder's express written permission. However, users may print, download, or email articles for individual use. 